\title{
Predatory Scholarly Publishing
}

Scholarly publishing is a very unique business. In a typical business, you have two parties: sellers and buyers. In scholarly publishing you also have sellers and buyers, these are the publishers and

the research libraries. However, you have two additional parties. On one side, you have authors, who freely and eagerly provide content ("publish or perish"). On the other side, there are editors and reviewers, who act as gatekeepers. They do so for a variety of reasons: sometimes for financial remuneration, but mostly out of civic duty and to gain scholarly prestige.

For scholarly publishing to be successful as a business, publishers must convince libraries to subscribe to their publications. Because budgets have become tighter over the last few years, librarians are quite resistant to increase their subscription inventory. The trend, in fact, is to prune, prune, and prune. Librarians, therefore, must be convinced of a journal's high quality before adding it to their subscription inventory. This resistance by libraries has been an important force for maintaining quality in scholarly publishing.

Recent trends have upset this delicate balance between publishers, libraries, authors, and editors, by freeing publishers from the need to get libraries to subscribe. Here is an example:

I regularly receive email solicitations such as: "Dear Author, as a general chair of GESTS, I am happy to invite you for the acceptance of your paper [sic] to be published in the GESTS International Transactions." (GESTS stands for Global Engineering, Science, and Technology Society.) The offer even provides volume and issue numbers. One has to read further down the invitation to find the coy reference to "registration fees." Again, this may seem like a scam, but a quick Web search finds many bibliographies that include publications in the GESTS International Transactions. Apparently, the publish-or-perish pressure creates a market, and enterprising publishers are keen to meet the demand. By shifting the costs to authors, GESTS is freed from dealing with librarians.

Here is another tantalizing offer: "Dear Professor Vardi, we would like to invite you as keynote speaker for one of the next WSEAS Conferences." This may seem as a genuine invitation to a bona fide scientific meeting, until one encounters a sentence such as "So, our plenary speakers can publish a minimum of one paper, maximum of three papers, without registration fees" and "New prospective plenary speakers must send their CV to ..." You can find a vigorous online debate on the precise nature of the WSEAS conferences, with allegations that the organizer is an enterprising academic, providing a forum where needy scholars can publish without battling hypercritical reviewers.

So what has upset the traditional scholarly publishing marketplace? On one hand, digital publishing has gained legitimacy. In fact, there are many high-quality publications that are published purely digitally. On the other hand, the growing popularity of open-access publishing popularized the author-pays model, in which publishers obtain revenues from author fees rather than from subscription fees. While there is nothing inherently wrong with the author-pays model, the removal of libraries from the equation created an unbalanced system: both publishers and authors want to publish, while libraries have little say. Editors and reviewers may try to uphold quality, but their power is diminished when publishers and authors are so eager to publish. (I resigned a few years ago from the editorial board of a prominent proceedings series, foregoing an annual honorarium of $€ 6,000$, when I realized quality was declining as publishing decisions were made by the publisher rather than by the editorial board.) This new imbalance in scholarly publishing has given rise to "predatory" publishing, whose main goal is to generate profits rather than promote scholarship. An informal directory of predatory publishers and journals has over 50 entries (see http://scholarlyoa.com/).

As I have written previously, I believe the partnership that once existed between the scholarly community and commercial publishers is fundamentally broken. Frankly, I do not understand why Elsevier is practically the sole target for the recent wrath directed at scholarly publisher. Elsevier is no worse than most other commercial publishers, just bigger, I believe. While not all commercial publishers are predatory publishers, they are all primarily driven by profits, which creates a conflict of interest between publishers and authors. The future of scholarly publishing belongs to association publishing, where the members are the publishers, authors, editors, and reviewers, sharing commitment to scholarship.

Moshe Y. Vardi, EDITOR-IN-CHIEF 